\title{
Cauda Equina Syndrome Caused by Idiopathic Epidural Lipomatosis
}

\author{
Yun Seong $\mathrm{Kim}^{1}$, Chang II Ju${ }^{2}$, Seok Won $\mathrm{Kim}^{2}$, Hyeun Sung $\mathrm{Kim}^{3}$ \\ Departments of ${ }^{1}$ Internal Medicine, ${ }^{2}$ Neurosurgery, Chosun University College of Medicine, Gwangju, \\ ${ }^{3}$ Department of Neurosurgery, Nanoori Hospital, Suwon, Korea
}

Spinal epidural lipomatosis (SEL) is a rare condition that presents as a back pain with progressive neurologic symptoms. Most affected patients are obese and receiving steroid therapy, or have an endocrinopathies. We report a rare case of cauda equina syndrome caused by SEL in a non-obese healthy young man without any evident traumatic episode. A healthy 19-year-old man, who had experienced lower back pain for two months, visited our emergency room because of the sudden development of motor weakness and voiding difficulty. Lumbar magnetic resonance image revealed extradural fat compressing the cauda equina. Urgent decompression via posterior laminectomy and excision of excess epidural fat resulted in an immediate symptom improvement.

Key Words: Cauda equina syndrome $\cdot$ Epidural $\cdot$ Lipomatosis

\section{INTRODUCTION}

Spinal epidural lipomatosis (SEL) is caused by excessive deposition of adipose tissue in the spinal canal, causing spinal cord or cauda equina compression ${ }^{8)}$. The majority of cases have been reported in morbidly obese patients receiving steroid therapy, or suffering from endocrinopathies, such as Cushing's syndrome or hypothyroidism in the thoracic spine ${ }^{2,3,11,12)}$. Here, we describe the case of a young patient discovered to have an epidural lipomatosis after the development of cauda equina syndrome and include a review of the literature.

\section{CASE REPORT}

The patient was a healthy 19-year-old man who had experienced back pain for 2 months prior to presentation, but had received no specific treatment. His visit to our emergency room was prompted by the development of motor weakness of the lower extremities and voiding difficulty on the day of the visit. He denied any recent history of trauma. A physical exami-

- Received: July 6, 2015 - Revised: September 11, 2015

- Accepted: September 21, 2015

Corresponding Author: Seok Won Kim, MD, PhD

Department of Neurosurgery, Chosun University College of Medicine,

365 Pilmun-daero, Dong-gu, Gwangju 61453, Korea

Tel: +82-62-220-3126, Fax: +82-62-227-4575

E-mail: ns64902@hanmail.net/chosunns@chosun.ac.kr

œThis is an Open Access article distributed under the terms of the Creative

Commons Attribution Non-Commercial License (http://creativecommons.org/ licenses/by-nc/3.0/) which permits unrestricted non-commercial use, distribution and reproduction in any medium, provided the original work is properly cited. nation revealed a body weight of $60 \mathrm{~kg}$ and a height of $175 \mathrm{~cm}$, his body mass index was $19.6 \mathrm{~kg} / \mathrm{m}^{2}$, which was within the normal range, and laboratory test findings, which included full blood count, electrolytes, creatinine, liver function test, vitamin B12 and folate, urine analysis and culture, thyroid function test, adrenocorticotropic hormone, and cortisol, were all unremarkable. However, a neurological examination revealed a reduction in patellar and Achilles tendon reflex in both legs, motor weakness (Grade I/Grade I), and sensory loss in L4, L5, and S1 with a radicular distribution. Plain radiographs of the lumbar spine showed no abnormalities. Magnetic resonance imaging (MRI) of the lumbar region showed a posterior compressing mass lesion of increased signal intensity on T1 and T2 weighted images in the epidural space, suggesting epidural lipomatosis at the L3-L4, L4-L5 and L5-S1 levels (Fig. 1). Due to the development of motor weakness and voiding difficulty, urgent decompressive laminectomies were performed at L3, L4, and L5 with fat debulking (Fig. 2). Subsequent histological examination revealed nodular proliferation of mature fat cells, consistent with lipomatosis. The patient realized a good postoperative outcome and experienced an immediate considerable symptom improvement. At one year after surgery, he was able to walk without mechanical assistance (Grade V/Grade V) and had returned to fulltime work at a university.

\section{DISCUSSION}

SEL describes the excessive deposition of histologically normal adipose tissue in the spinal canal, causing compression 


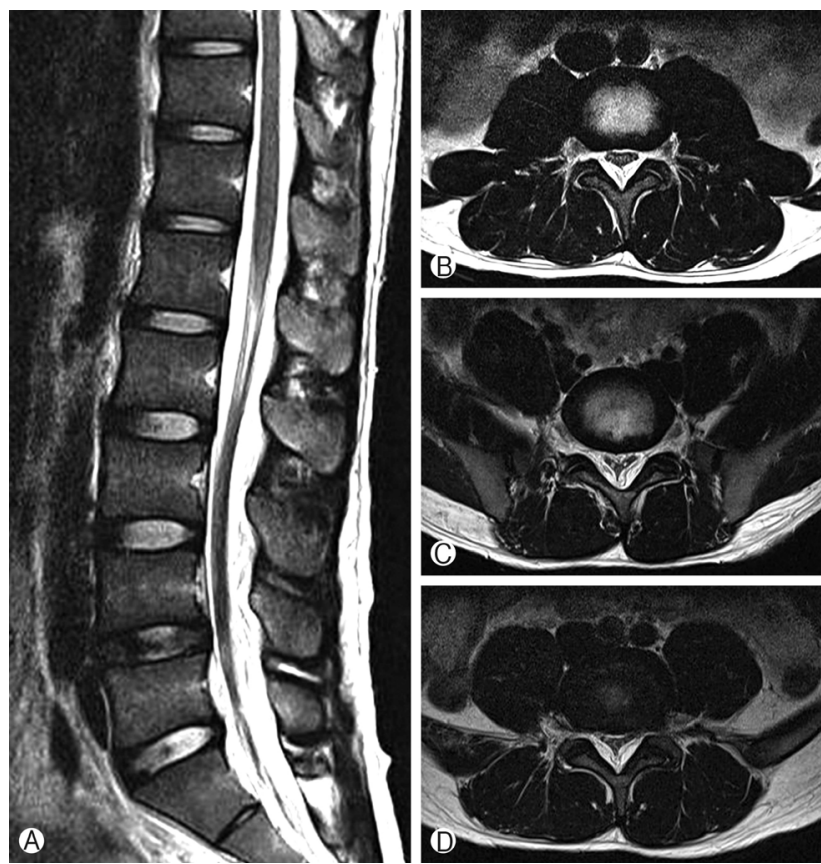

Fig. 1. Sagittal and axial T2 weighted images of the magnetic resonance image show a posterior epidural mass with compressing the cauda equina extending from $L 2$ to $S 1$ segment with high signal intensity. (A) Sagittal T2 weighted image, (B, C, D) Axial T2 weighted images at L3-4, L4-5, and L5-S1 level show classic "Y-sign".

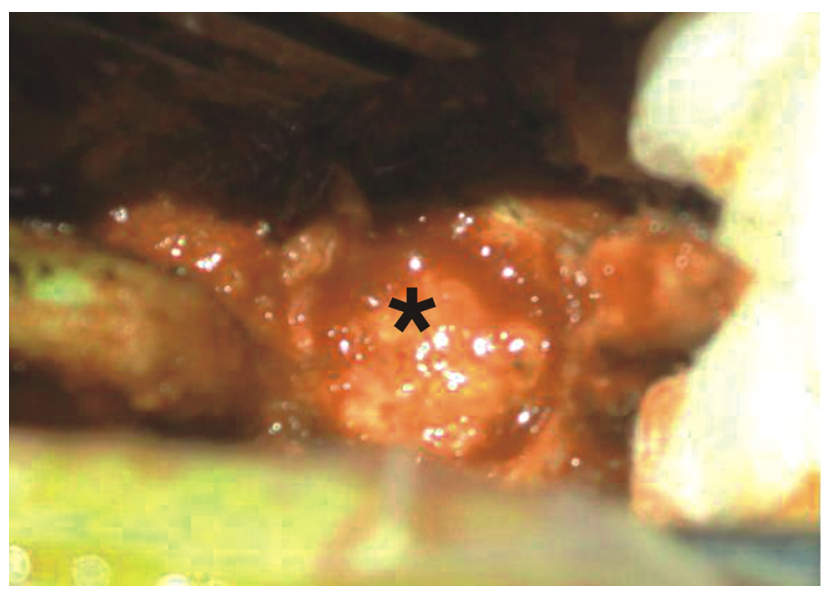

Fig. 2. Intraoperative photograph demonstrates the epidural lipomatosis $(*)$.

of the spinal cord or cauda equina. This deposition typically occurs posterior to the cord in the thoracic spine in overweight patients ${ }^{7}$. It has been well established that the main etiological factors of SEL are related to endocrine dysfunctions, such as those associated with Cushing's disease, hypothyroidism, obesity, iatrogenic steroid treatment of immune disorders, COPD, and transplantation ${ }^{4,5)}$. However, it can be present even in the absence of endocrinopathies and in nonobese patients. The term 'idiopathic SEL' is applied to describe cases without definitive predisposing factors, and the occurrence of idiopathic SEL in non-obese young patient is exceptional. Furthermore, our patient was not receiving steroids or has any type of endocrinopathy. Haddad et al. ${ }^{5)}$ first hypothesized that idiopathic SEL is a byproduct of obesity, involving gradual overgrowth of epidural fat resulting in spinal cord and nerve roots compression.

Idiopathic SEL causing neurological deficits occurs more frequently in the thoracic than in the lumbar spine. Patients may present with progressive and long-standing complaints of pain, weakness, numbness, incontinence, ataxia, abnormal reflexes, and rarely paralysis. Epidural lipomatosis commonly presents with localized chronic pain, which has often lasted months to several years, followed by progressive or sudden neurologic deficits. Sensory changes with numbness, paresthesias, or radicular symptoms are also common. Bowel and bladder incontinence have been reported, but appear to be rare $^{12)}$. Lower-extremity weakness and sensory change are the most common finding during physical examination, though decreased pinprick sensation and altered reflexes are frequently encountered. Obviously, symptoms are somewhat dependent on the level of canal compromise (spinal cord, conus medullaris, or cauda equina) $)^{9}$.

Plain radiographs of the lumbar spine are usually normal, but MRI is the imaging tool of choice. Canal compression with obliteration of cerebrospinal fluid spaces can be appreciated on axial and sagittal MR images, and high-signal intensity on T1-weighted images and intermediate signal intensity on T2-weighted images are characteristics of adipose tissue. Moreover, short T1 inversion recovery (STIR) sequence may be useful for confirmation of diagnosis as lipid is hypointense in this sequence. But in our patient, regretfully STIR sequence was not performed. Circumferential compression of the thecal sac is referred to as "Y-sign", a trifid appearance of thecal sac, characteristics in axial imaging ${ }^{6}$. Borre et al. ${ }^{1)}$ developed four categories of MRI grading of lumbosacral epidural lipomatosis attending to the spatial relation between dural sac and epidural fat. But, no reports have answered the question of direct relation between grading system of lipomatosis and symptom development. Treatments relies on the severity of neurological deficits. Just weaning of steroids and weight loss or treatment of endocrinopathy can achieve good results. But our patient had neither obesity nor steroid treatment. Surgical intervention is indicated in case of severe or progressive neurologic deficits. Recovery can be either immediate or occur over several months, although reports indicate that the majority of patients experience improvements in neurological symptoms immediately after surgical intervention. Furthermore, patients 
with pathological conditions in the lumbar (cauda equina) region tend to make better recoveries following surgical decompression than patients with pathological conditions in the thoracic region ${ }^{10)}$.

\section{CONCLUSION}

We report a rare case of idiopathic SEL causing cauda equina syndrome in a non-obese young patient. Although rare, idiopathic SEL should be considered as a cause of cauda equina syndrome.

\section{REFERENCES}

1. Borré DG, Borré GE, Aude F, Palmieri GN: Lumbosacral epidural lipomatosis: MRI grading. Eur Radiol 13:1709-1721, 2003

2. Chapman PH, Martuza RL, Poletti CE, Karchmer AW: Symptomatic spinal epidural lipomatosis associated with Cushing's syndrome. Neurosurgery 8:724-727, 1981

3. Choi SM, Choi G, Lee SH: Cauda equina syndrome due to spinal epidural lipomatosis. Korea J Spine 2:65-67, 2005

4. Fassett DR, Schmidt MH: Spinal epidural lipomatosis: a review of its caused and recommendations for treatment. Neurosurg
Focus 16:1-3, 2004

5. Haddad SF, Hitchon PW, Godersky JC: Idiopathic and glucocorticoid-induced spinal epidural lipomatosis. J Neurosurg 74: 38-42, 1991

6. Kuhn MJ, Youssef HT, Swan TL, Swenson LC: Lumbar epidural lipomatosis: the "Y" sign of thecal sac compression. Comput Med Imaging Graph 18:367-372, 1994

7. Kumar K, Nath RK, Nair CP, Tchang SP: Symptomatic epidural lipomatosis secondary to obesity. Case report. J Neurosurg 85 : 348-350, 1996

8. Lee SB, Park HK, Chang JC, Jin SY: Idiopathic thoracic epidural lipomatosis with chest pain. J Korean Neurosurg Soc 50:130133, 2011

9. Robertson SC, Traynelis VC, Follett KA, Menezes AH: Idiopathic spinal epidural lipomatosis. Neurosurgery 41:68-74, 1997

10. Roy-Camille R, Mazel C, Husson JL, Saillant G: Symptomatic spinal epidural lipomatosis induced by a long-term steroid treatment. Review of the literature and report of two additional cases. Spine (Phila Pa 1976) 16:1365-13671, 1991

11. Toshniwal PK, Glick RP: Spinal epidural lipomatosis: report of a case secondary to hypothyroidism and review of literature. J Neurol 234:172-176, 1987

12. Zampella EJ, Duvall ER, Sekar BC, Langford KH, Epstein AE, Kirklin JK, et al: Symptomatic spinal epidural lipomatosis as a complication of steroid immunosuppression in cardiac transplant patients. Report of two cases. J Neurosurg 67:760-764, 1987 